\title{
Kinetic, thermodynamics and equilibrium studies on the removal of Congo red dye using activated teak leaf powder
}

\author{
Vidyadhar V. Gedam ${ }^{1}$ (D) Pranay Raut ${ }^{2} \cdot$ Anup Chahande $^{2} \cdot$ Pranav Pathak $^{3}$
}

Received: 6 February 2018 / Accepted: 12 March 2019 / Published online: 27 March 2019

(c) The Author(s) 2019

\begin{abstract}
The present study investigates activated teak leaf powder (Tectona grandis) as a biosorbent for the effective removal of Congo red (CR) dye from aqueous solution. Biosorbent was characterized via Fourier transform infrared spectroscopy, scanning electron microscopy, Brunauer-Emmett-Teller and X-ray diffraction. The effect of different parameters, i.e., initial dye concentration, adsorbent dosage, contact time, $\mathrm{pH}$ and temperature, was studied in detail. The experimental data were interpreted and studied using Langmuir, Freundlich and Temkin isotherm, and Langmuir isotherm was observed to be best fit. The investigation shows the pseudo-second order is the prevailing kinetic mechanism during adsorption and the energy change $(\Delta G)$, enthalpy change $(\Delta H)$ and entropy change $(\Delta S)$ were $-5.101 \mathrm{~kJ} / \mathrm{mol}, 246.792776 \mathrm{~J} / \mathrm{mol} \mathrm{K}$ and $69.6771398 \mathrm{~kJ} /$ $\mathrm{mol}$, respectively. The results show that activated teak leaf powder can be a viable sorbent for the removal of CR dye from wastewater in a reasonable, economical and environmentally friendly way.
\end{abstract}

Keywords Tectona Grandis · Congo red (CR) dye · Adsorption isotherms · Kinetics models · Thermodynamic study

\section{Introduction}

Paper, textile, cosmetics, food, pharmaceutical and plastic industries discharge effluents containing highly colored dyes which are one of the major causes of environmental deterioration (Forgacs et al. 2004). The effluent of dye industries has various environmental issues which include high chemical oxygen demand (COD), delayed and stagnant growth of microorganisms, light trapping, etc. (Chen et al. 2003; Singh et al. 2013). Decomposition of some dyes present in

Vidyadhar V. Gedam

vgedam@nitie.ac.in

Pranay Raut

pranay.raut@gmail.com

Anup Chahande

anup.chahande@gmail.com

Pranav Pathak

pranav.pathak@mituniversity.edu.in

1 Environmental Engineering and Management, National Institute of Industrial Engineering (NITIE), Mumbai, India

2 Priyadarshini Institute of Engineering and Technology, Nagpur, India

3 MIT School of Bioengineering Sciences \& Research, Pune, India the effluent leads to health issues due to conversion into carcinogenic substances under anaerobic conditions (Chatterjee et al. 2009). Anionic dye is metabolized to benzidine, a human carcinogen, and causes an allergic reaction (Chatterjee et al. 2010). Congo red (CR) dye is being currently used for various applications such as laboratory aid, $\mathrm{pH}$ indicator, histological stains and textile industries (Garg et al. 2003). Dyes are recalcitrant organic molecules, resist aerobic digestion, are low biodegradable and are stable to light (Mondal 2008). Therefore, conventional biological wastewater treatment processes and methods are not enough and prevailing to treat them (Zhou et al. 2012). Various physical and chemical treatment processes such as adsorption, oxidation, coagulation followed by flocculation and advanced treatment techniques such as membrane separation, electrochemical degradation, ion exchange etc., can be effectively used to treat wastewater effluent of dyes industries (Gupta and Suhas 2009; Fan et al. 2008). Recently, adsorption is receiving much more attention among other available technologies due to its simplicity, ease of operation, low energy requirement and reuse capability (Silva et al. 2012). Activated carbon is the most efficient and frequently used adsorbent for the efficient removal of water-soluble dyes (Namasivayam et al. 1996). But the high cost and difficulty in regeneration are the main hurdles for its effective and long-term use at a 
large scale (Nasuha et al. 2011). Low-cost biosorbent was explored in detail by many researchers in developing and developed countries due to its local abundance, low toxicity and inexpensive regeneration. Various materials such as orange peel (Namasivayam et al. 1996), papaya seed (Hameed 2010; Nasuha et al. 2011), jackfruit peel (Hameed 2009) and chitosan (Rouf et al. 2015) were studied for effective dye removal. Adsorption of methylene blue dye (Bhattacharyya and Sharma 2005), Congo red dye (Bhattacharyya and Sharma 2004) and methyl orange and Congo red dye (Ibrahim et al. 2015) using neem leaf powder was studied in detail. Furthermore, basic dye and methylene blue using guava leaf powder (Singh and Srivastava 1999; Ponnusami et al. 2008) and teak leaf powder (TLP) (King et al. 2006) have also been investigated in detail. However, little research has been done to investigate the potential of adsorption using solid waste from plant leaf powder specifically TLP. The present research work examines potential applicability of activated carbon prepared from TLP as a biosorbent for the effective removal of anionic CR dyes. The distinct nature and features of biosorbent were analyzed via Fourier transform infrared spectroscopy (FTIR), scanning electron microscopy (SEM), Brunauer-Emmett-Teller (BET) and $\mathrm{X}$-ray diffraction (XRD). The effect of different physicochemical parameters which include initial dye concentration, adsorbent dosage, $\mathrm{pH}$, contact time and temperature along with adsorption isotherms, kinetics and thermodynamic parameters was also explored in detail.

\section{Materials and methods}

\section{Preparation of activated adsorbent}

The adsorbent material, i.e., teak leaf (Tectona Grandis), was collected from Nagpur, Maharashtra, India, which favors warm tropical climate for the growth of teak trees. It can withstand extremes of temperature with the maximum and minimum temperature of $39-40{ }^{\circ} \mathrm{C}$ and $13-17{ }^{\circ} \mathrm{C}$, respectively. Teak leaves were cleaned with distilled water to get rid of soil and dust and then dried till they become crispy. The dried teak leaves were crushed in a mortar-pestle and were sieved, and the fine fractions were separated. The fine fractions were then thermally activated in a muffle furnace at $500{ }^{\circ} \mathrm{C}$. The prepared sample was named as TLP and was kept in an airtight container for other experimentations without any chemical or physical treatment. The procedure used for adsorbent preparation and activation was performed as per standard procedure (Bhattacharyya and Sharma 2004; Ponnusami and Srivastava 2009; Reddy et al. 2012).
Table 1 Physical properties of TLP

\begin{tabular}{ll}
\hline Property & Value \\
\hline Moisture content (\%) & 2.8 \\
Volatile matter (\%) & 87 \\
Ash (\%) & 3.2 \\
Fixed carbon $(\%)$ & 7 \\
Bulk density $\left(\mathrm{kg} / \mathrm{m}^{3}\right)$ & 412 \\
\hline
\end{tabular}

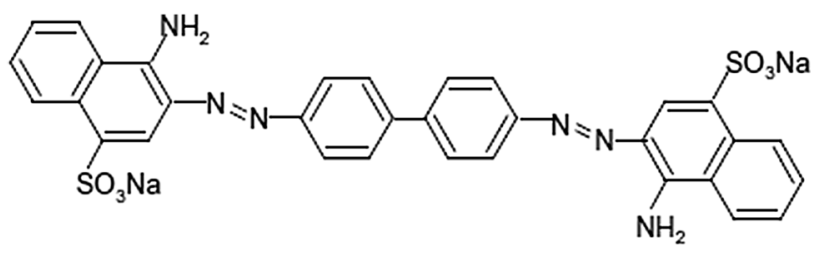

CONGO RED

Fig. 1 Chemical structure of Congo red (CR) dye

\section{Adsorbate}

CR dye an anionic azo dye [1-naphthalenesulfonic acid, 3, 3-(4,4-biphenylenebis(azo))bis(4-aminodisodium)] used during the study was procured from Fisher Scientific, India (C.I. number $=22,120, \mathrm{MW}=696.7 \mathrm{~g} / \mathrm{mol}$. and $\lambda_{\max }=497 \mathrm{~nm}$ ). Physicochemical properties and chemical structure of CR dye are highlighted in Table 1 and Fig. 1, respectively. During experimentation, exactly $1000 \mathrm{mg} / \mathrm{l}$ of the stock solution was prepared by adding $1000 \mathrm{mg}$ of $\mathrm{CR}$ dye in $1 \mathrm{~L}$ of double-distilled water, and during the initial dye concentration experimentations design, the solutions were diluted from the stock solution.

\section{Analytical instrumentation}

During experimentation, the dye concentrations were analyzed by a double-beam UV-visible spectrophotometer (Shimadzu UV-1601). The pH meter (ELICO model LI-127, India) was used for $\mathrm{pH}$ measurement. The distinct properties, surface morphology and features of activated TLP were analyzed via Fourier transform infrared spectrophotometer (FTIR) (PerkinElmer Spectrum-BX USA) and X-ray diffraction (XRD) using CuKa (Rigaku MiniFlex II). Before adsorption and after adsorption, particle geometry and structure were identified and recorded by scanning electron microscopy (SEM) analysis. The SEM of activated TLP was performed using model (6380A, JEOL Ltd., Tokyo, Japan). Furthermore, the surface area of TLP was determined by a single-point Brunauer-Emmett-Teller (BET) analysis using model Smart Sorb 92/93, surface area analyzer. 


\section{Point of zero charge $\left(\mathrm{pH}_{\mathrm{zpc}}\right)$}

The zero surface charge $\left(\mathrm{pH}_{\mathrm{zpc}}\right)$ of activated TLP was determined by the standard method of solid addition (Ho and Mckay 1998; Reddy et al. 2012; Ribeiro et al. 2012). During $\mathrm{pH}_{\mathrm{zpc}}$ analysis, exactly $40 \mathrm{ml}$ of $0.1 \mathrm{M} \mathrm{KNO}_{3}$ was used in $100-\mathrm{ml}$ conical flasks. Either $0.1 \mathrm{~N} \mathrm{HCl}$ or $\mathrm{NaOH}$ was added to adjust initial $\mathrm{pH}(\mathrm{pHi}$ ) of solutions (between 2 and 12), and the volume of each flask was maintained to $100 \mathrm{ml}$ by adding $\mathrm{KNO}_{3}$. The initial $\mathrm{pH}(\mathrm{pHi})$ was then accurately analyzed by $\mathrm{pH}$ meter (Systronics pH system 361 Model, India). Exactly $0.05 \mathrm{gm}$ of activated TLP was added to each flask, followed by secured capping. The solution was kept in an orbital shaker for $150 \mathrm{~min}$ (min.) at room temperature and allowed to reach equilibrium. After equilibrium was reached, final $\mathrm{pH}(\mathrm{pHf})$ was measured. The graph between $\mathrm{pH}(\Delta \mathrm{pH})$ against $\mathrm{pHi}$ was then plotted and the $\mathrm{pH}_{\mathrm{zpc}}$ was calculated.

\section{Batch kinetic studies}

The effect of different influencing parameters such as initial dye concentration, adsorbent dose, contact time, temperature and $\mathrm{pH}$ on the removal of CR dye was studied in detail. During batch studies, 250-ml Erlenmeyer conical flask in an orbital shaker was maintained at $30^{\circ} \mathrm{C}$ and $100 \mathrm{rpm}$ for $24 \mathrm{~h}$ followed by centrifugation. The batch experimentation was done with a known amount of adsorbent in $100 \mathrm{ml}$ of aqueous $\mathrm{CR}$ dye solution. The remaining dye concentration in the flask was measured spectrophotometrically at $497 \mathrm{~nm}$. The effect of $\mathrm{pH}$ on the removal of $\mathrm{CR}$ dye was analyzed over a wide range of $\mathrm{pH}(2-10)$. The $\mathrm{pH}$ of the solution was maintained by adding few drops of $0.1 \mathrm{~N} \mathrm{HCl}$ and $0.1 \mathrm{~N} \mathrm{NaOH}$ to maintain acidic and alkaline conditions. During the study, exactly $100 \mathrm{ml}$ of CR dye solution of $20 \mathrm{ppm}$ was used with $0.1 \mathrm{gm}$ of adsorbent over the $\mathrm{pH}$ range of $2-10$. The solution was then centrifuged at $3000 \mathrm{rpm}$, and the supernatant liquid was used for further analysis. The effect of TLP dose on the CR dye removal was studied by taking $10-250 \mathrm{mg}$ of TLP with $100 \mathrm{ml}$ of $20 \mathrm{ppm}$ CR dye solution and was agitated at $100 \mathrm{rpm}$ for $150 \mathrm{~min}$ at room temperature. To study the effect of contact time, exactly $0.1 \mathrm{gm}$ of activated TLP was used in $100 \mathrm{ml}$ of $20 \mathrm{ppm}$ CR dye solution. The solution was then kept in an orbital shaker at pH 6.0 and then analyzed for dye concentration. The effect of initial dye concentrations was studied by adding $150 \mathrm{mg}$ of activated TLP in $100 \mathrm{ml}$ of CR dye solution of 10-100 ppm at constant $\mathrm{pH}$ 6.0. The prepared sample solution was then centrifuged and analyzed. Similarly, the effect of temperature was studied at 30,40 and $60{ }^{\circ} \mathrm{C}$. The solution was withdrawn at a predetermined time after centrifugation at $3000 \mathrm{rpm}$ for five min, and the supernatant was then analyzed spectrometrically.

The amount of adsorption at time $t, q_{\mathrm{e}}$, was calculated using Eq. 1.
$q_{\mathrm{e}}=\frac{\left(C_{0}-C_{\mathrm{e}}\right) \times V}{W}$

where $C_{0}$ and $C_{\mathrm{e}}$ are the dye concentration $(\mathrm{mg} / \mathrm{l})$ at initial and at equilibrium, respectively, $V$ is the volume of solution and $W$ is the mass (gm) of adsorbent.

The \% dye removal was determined using Eq. 2 as fallows.

$\%$ adsorption $=\frac{\left(C_{0}-C_{\mathrm{e}}\right)}{C_{0}} \times 100$

where $C_{0}$ and $C_{\mathrm{e}}$ are the dye concentration $(\mathrm{mg} / \mathrm{l})$.

\section{Adsorption kinetics and model fitting}

To explore the adsorption kinetics of CR dye, the pseudofirst-order and pseudo-second-order model was adopted to fit the experimental findings using the following equations. These models were selected to study the controlling mechanism of CR dye adsorption from aqueous solution.

The Lagergren first-order kinetic model is given by Eq. 3 .

$\ln \left(q_{\mathrm{e}}-q_{t}\right)=\ln q_{\mathrm{e}}-k_{1} t$

The pseudo-second-order kinetic model is given by Eq. 4 .

$\frac{\mathrm{t}}{\mathrm{q}_{t}}=\frac{1}{\mathrm{k}_{2} q_{\mathrm{e}}^{2}}+\left(\frac{1}{q_{\mathrm{e}}}\right) t$

where $k_{1}(1 / \mathrm{min})$ and $k_{2}(\mathrm{~g} / \mathrm{mg} \min$.) are rate constants for pseudo-first- and second-order adsorption, respectively, $q_{\mathrm{e}}$ is the quantity of adsorbed dye at equilibrium $(\mathrm{mg} / \mathrm{g}), q_{t}$ is the dye amount adsorbed at time $t(\mathrm{mg} / \mathrm{g})$ and $t$ is the contact time ( $\min )$.

\section{Adsorption isotherms}

Various theoretical and empirical models were established and studied to characterize the different types of adsorption isotherms. The Langmuir (Eq. 5), Freundlich (Eq. 6) and Temkin isotherms (Eq. 7) were among the most frequently used. During the present study, the relationship between concentration and CR dye uptake was investigated via Langmuir, Freundlich and Temkin isotherms, respectively (Okoli et al. 2015), which is shown as follows.

$\frac{C_{\mathrm{e}}}{q_{\mathrm{e}}}=\frac{C_{\mathrm{e}}}{q_{\mathrm{m}}}+\frac{1}{q_{\mathrm{m}} K_{\mathrm{L}}}$

$\log q_{\mathrm{e}}=\log k_{\mathrm{f}}+\frac{1}{n} \log C_{\mathrm{e}}$

where $q_{\mathrm{e}}$ is the quantity of dye adsorbed per precise quantity of adsorbent $(\mathrm{mg} / \mathrm{g}), C_{\mathrm{e}}$ is the equilibrium concentration of the solution $(\mathrm{mg} / \mathrm{l}), q_{\mathrm{m}}$ is the maximum amount of adsorbent 
ions essential to form a monolayer $(\mathrm{mg} / \mathrm{g})$ and $K_{\mathrm{L}}$ is the Langmuir adsorption constant.

By experimental data, the Freundlich equilibrium constants can be calculated from the intercept and slope of the linear plot of $\ln q_{\mathrm{e}}$ against $\ln C_{\mathrm{e}}$. Here, $k_{\mathrm{f}}$ is the Freundlich isotherm constant and $1 / \mathrm{n}$ is the heterogeneity factor.

The Temkin isotherm can be expressed in linear form as shown in Eq. 7.

$q_{\mathrm{e}}=\mathrm{B} \ln \mathrm{A}+\mathrm{B} \ln C_{\mathrm{e}}$

The adsorption data can be analyzed according to the above equation. A plot of $q_{\mathrm{e}}$ against $\ln C_{\mathrm{e}}$ gives the constants $\mathrm{A}$ and $\mathrm{B}$. Here, $A$ is the isotherm equilibrium binding constant $(\mathrm{L} / \mathrm{g})$ and $\mathrm{B}$ is the heat of sorption constant $(\mathrm{J} / \mathrm{mol})$ for Temkin isotherm.

\section{Thermodynamic studies}

During the present investigation, thermodynamic parameters, i.e., free energy change $(\Delta G)$, enthalpy change $(\Delta H)$ and entropy change $(\Delta S)$, were calculated using empirical Eqs. 8, 9, 10 and 11 .

$\Delta G=-2.303 R T \ln K_{\mathrm{D}}$

$\Delta G=\Delta H-T \Delta S$

$K_{\mathrm{D}}=\frac{C_{\mathrm{s}}}{C_{\mathrm{e}}}$

$\ln K_{\mathrm{D}}=\frac{\Delta S}{R}-\frac{\Delta H}{R T}$

where $K_{\mathrm{D}}$ is the distribution coefficient, $C_{\mathrm{s}}$ is the concentration of dye solution at equilibrium, $C_{\mathrm{e}}$ is the dye solution concentration at equilibrium into solution $(\mathrm{mg} / \mathrm{l}), R$ is the universal gas constant $\left(8.314 \mathrm{~J} / \mathrm{mol}^{\circ} \mathrm{k}\right), T$ is the temperature $\left({ }^{\circ} \mathrm{C}\right)$ and $\Delta H$ and $\Delta S$ were calculated from the graph of $\ln K_{\mathrm{D}}$ versus $1 / T$ as slope and intercept, respectively.

\section{Statistical method and data analyses}

All the experiments were performed in triplicates, and mean values were specified. The calculated standard deviation (\%) was observed minimal and therefore not represented. All graphs were prepared using MS Excel software.

\section{Results and discussion}

\section{Point of zero charge $\left(\boldsymbol{P}_{\mathrm{zpc}}\right)$}

Figure 5 shows the graph of $\Delta \mathrm{pH}$ versus $\mathrm{pH}_{\text {initial }}$. The $P_{\mathrm{zpc}}$ of activated TLP was found to be 8.1. The result shows that the basic functional groups are predominant on the solid surface of the adsorbent. The $\mathrm{pH}$ below this is favorable for adsorption of an anionic dye. The $P_{\mathrm{zpc}}$ of activated TLP is slightly less compared to that of waste processing mustard oil, i.e., pH 9.0 (Magriotis et al. 2014), while it is well above compared to waste radish, i.e., $\mathrm{pH} 3.4$, and jatropha oil cake, i.e., pH 5.0 (Muthusamy et al. 2014; Dawood and Sen 2012).

\section{Characterization of adsorbent}

Figures 2 and 3 show the Fourier transform infrared spectroscopy (FTIR), and Figs. 4 and 5 show the X-ray diffraction (XRD) spectrum of TLP before and after adsorption,
Fig. 2 FTIR spectrum of TLP before adsorption
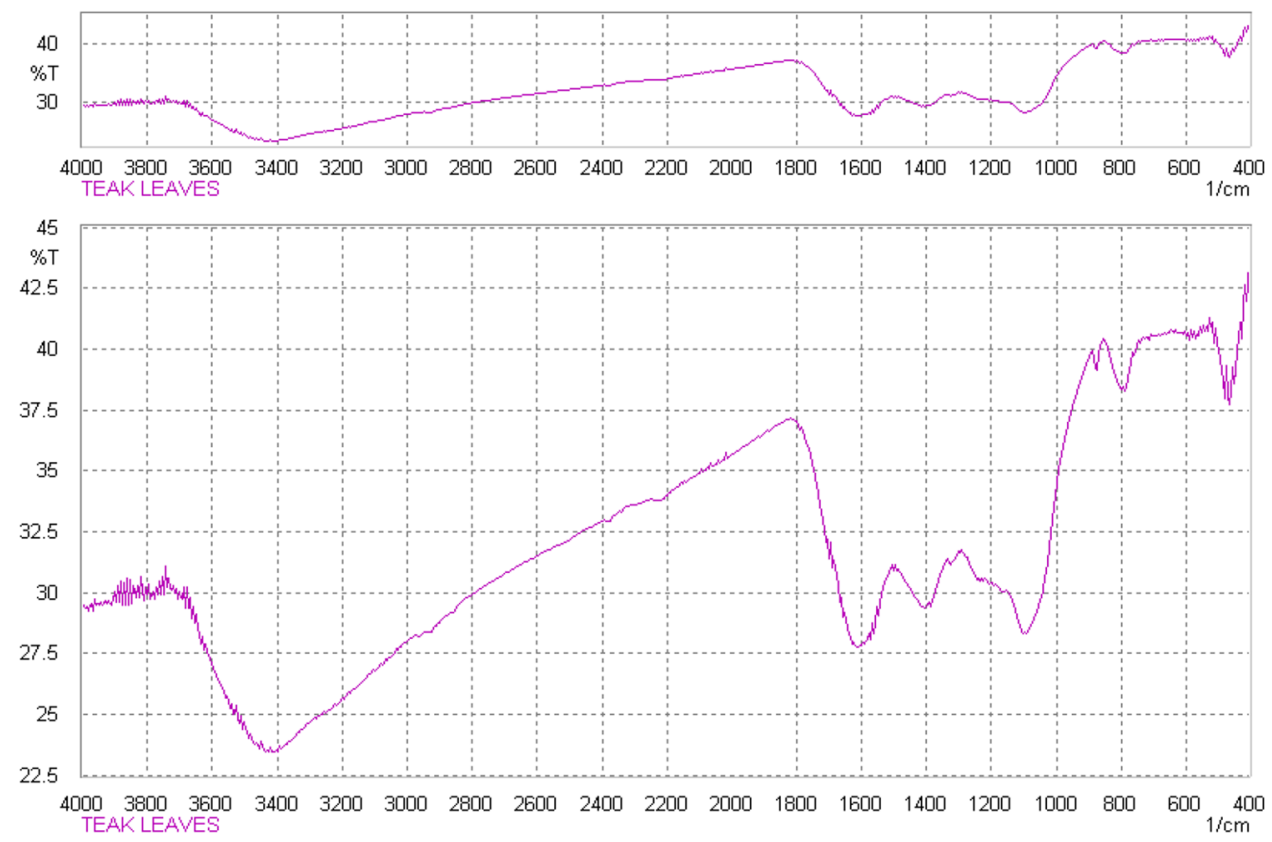
Fig. 3 FTIR spectrum of TLP after adsorption
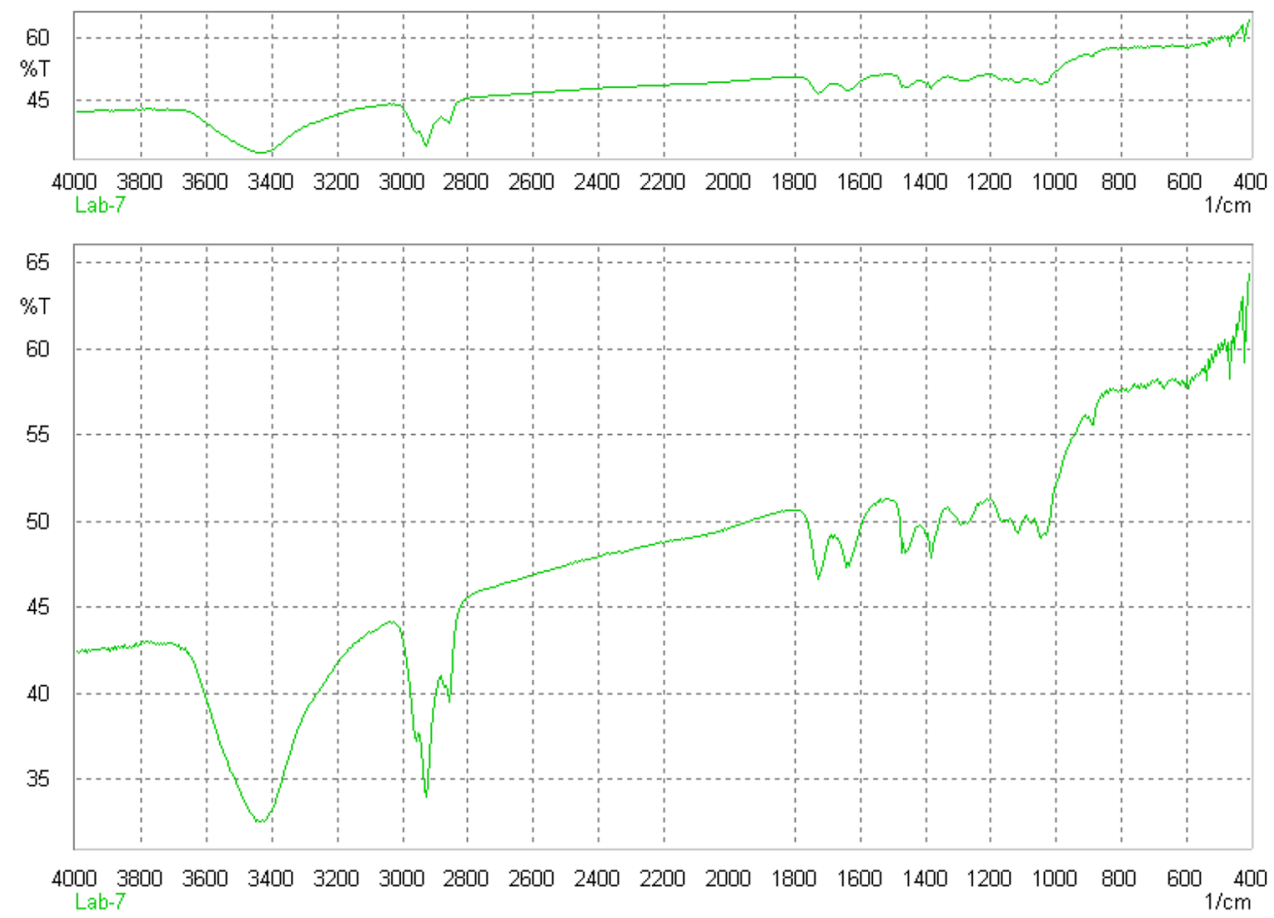

respectively. The before-adsorption FTIR spectra show the presence of prominent and intense peaks at $1100 \mathrm{~cm}^{-1}$, $1400 \mathrm{~cm}^{-1}$ and $1600 \mathrm{~cm}^{-1}$, respectively. The peaks confirm that alkene, ether and aromatic carbon rings are present (carbon bond, i.e., $\mathrm{C}=\mathrm{C}$ ) in prepared activated TLP (Hesas et al. 2013). The FTIR spectra after adsorption show the presence of prominent and intense peaks at $1400 \mathrm{~cm}^{-1}$, $1700-1600 \mathrm{~cm}^{-1}$ and $2900-3000 \mathrm{~cm}^{-1}$ which show the presence of alkene, ether, an aromatic carbon ring and $\mathrm{C}-\mathrm{H}$ stretch from alkanes (Hesas et al. 2013). Similarly, the XRD spectra show the intense and well-identified peak at $2 \theta$ degree of 757 which highlight the presence of the crystalline structure. The intensity of the highly organized peaks

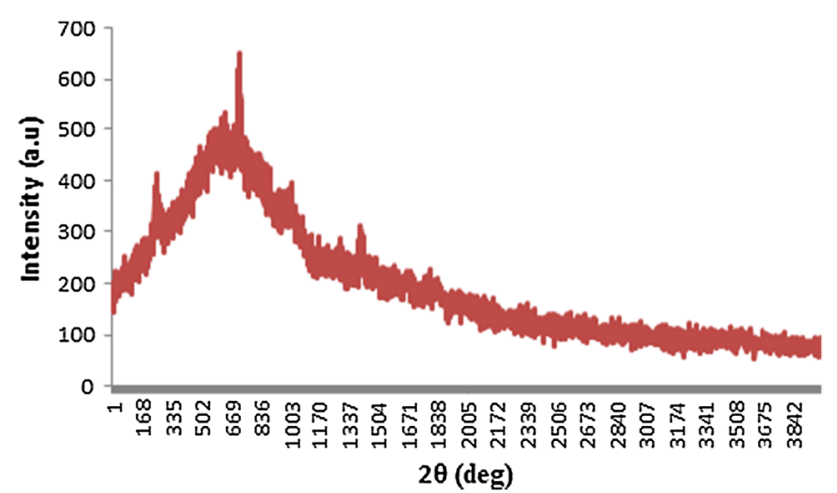

Fig. 4 XRD spectrum of TLP before adsorption

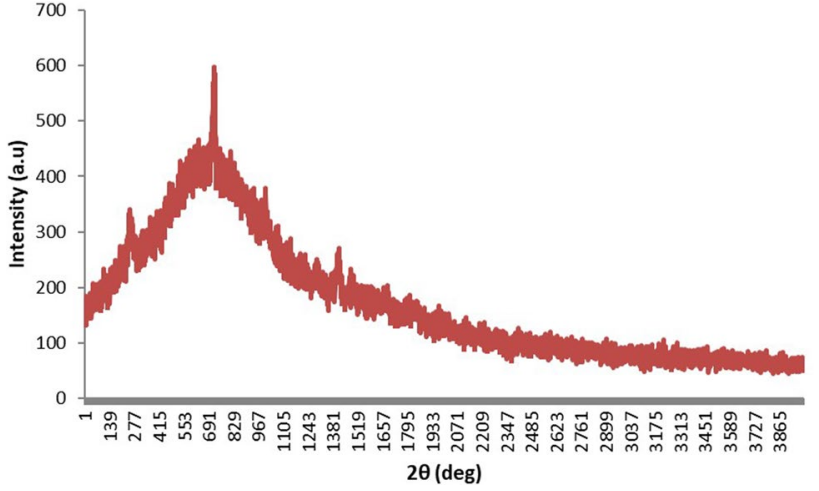

Fig. 5 XRD spectrum of TLP after adsorption

was not diminished after adsorption as shown in Fig. 5. Figure 5 highlights that the adsorption of CR dye will be on the upper layer of the crystalline structure probably dominated because of physical adsorption. The before-adsorption and after-adsorption SEM images are shown in Figs. 6 and 7, respectively. The results show flex-like geometry having uniform pores (macropores and micropores) on the surface of TLP before adsorption. The pores formation may be due to the carbonization at high temperatures (Fig. 6). After CR dye adsorption (Fig. 7), the pores of TLP are filled due to the adsorption of $\mathrm{CR}$ dye which may confirm the adsorption phenomenon between the CR dye and TLP. Furthermore, the single-point BET surface area of TLP was found to be 


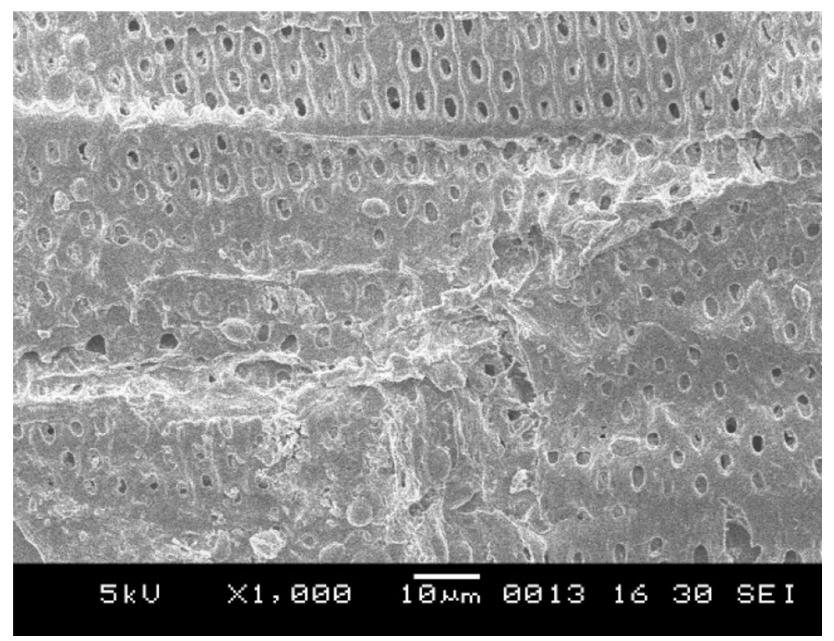

Fig. 6 SEM analysis of raw TLP before adsorption

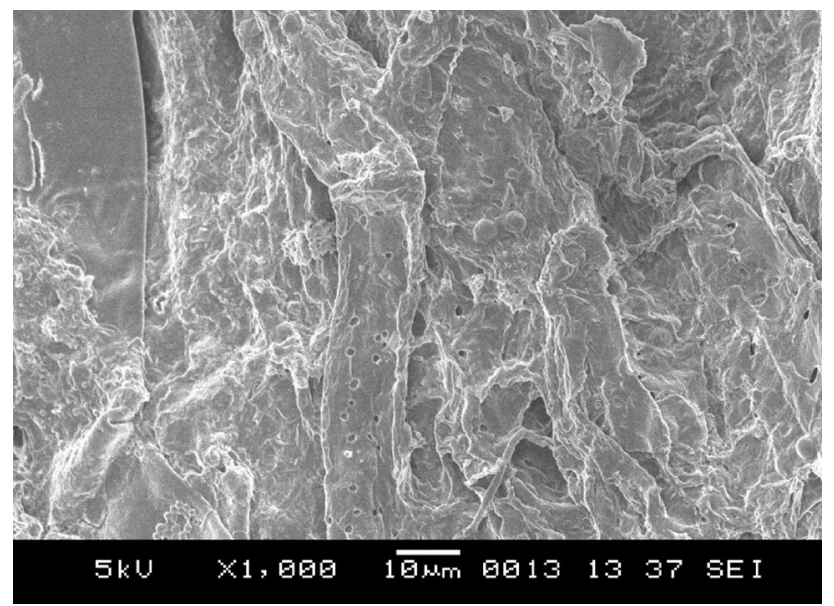

Fig. 7 SEM analysis of raw TLP after adsorption

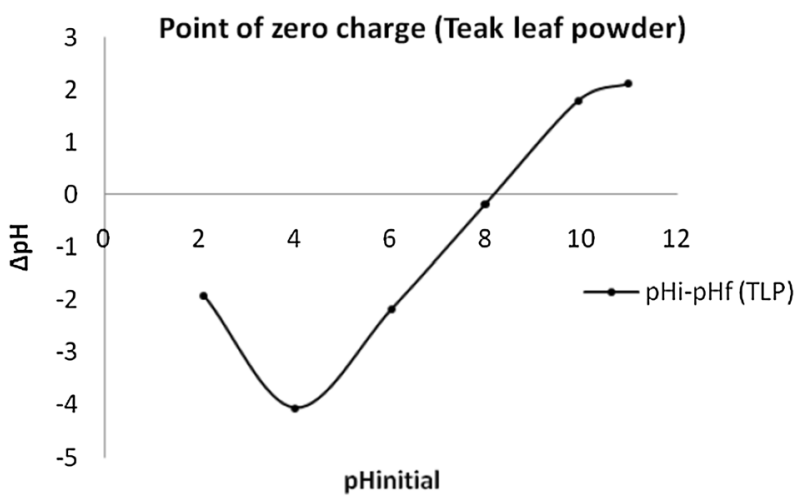

Fig. 8 Point of zero charge $\left(P_{\mathrm{zpc}}\right)$ of activated teak leaf powder (TLP). *Adsorbent dose $-0.05 \mathrm{~g}$, agitation time $-150 \mathrm{~min}$, temperature $-30{ }^{\circ} \mathrm{C}$, volume $-100 \mathrm{ml}$

$26.35 \mathrm{~m}^{2} \mathrm{~g}^{-1}$. The surface area was measurable and was mostly due to the presence of pores on the surface of TLP (Fig. 8).

\section{Effect of pH}

The $\mathrm{pH}$ is a master variable for adsorption on adsorbent. Studies show that the CR dye solution changes its color from dark blue to red at acidic $\mathrm{pH}$ and alkaline $\mathrm{pH}(10-12)$, respectively (Kaur et al. 2013). Therefore, the effect of $\mathrm{pH}$ on CR dye removal was studied at $\mathrm{pH}$ of $2-10$ as shown in Fig. 9. Figure 9 shows that the amount of dye adsorbed was increased from $\mathrm{pH} 2$ to 6 , slightly decreased from 6 to 8 and then kept decreasing up to $\mathrm{pH} 10$. This was mostly attributed due to the $P_{\text {zpc }}$ of activated TLP which was observed to be 8.1. When solution $\mathrm{pH}$ is less than the $P_{\mathrm{zpc}}$ of activated TLP, sorbent surface will have a net positive charge. This charge facilitates electrostatic attraction between negatively charged anionic CR dye and positively charged sorbent surface; therefore, percentage removal of CR dye increases (Kaur et al. 2013; Ibrahim et al. 2015).

\section{Effect of adsorbent dose}

The adsorbent dose effect on the removal of CR dye is shown in Fig. 10. Figure 10 reveals that removal of CR dye increases to a certain limit, i.e., $150 \mathrm{~g}$, and after that, there is no significant removal. This may be mostly due to a conglomeration of activated TLP as there is no significant increase in the effective specific surface area and adsorption sites. Furthermore, an increase in adsorption with adsorbent dose was attributed due to the increased surface area and the availability of more adsorption sites (Hameed 2009; Reddy et al. 2012). Thus, $150 \mathrm{mg}$ was taken as the optimum adsorbent dose for further study.

\section{Effect of Initial dye concentration, contact time and temperature}

The initial dye concentration, contact time and temperature have a substantial effect on the removal of CR dye from

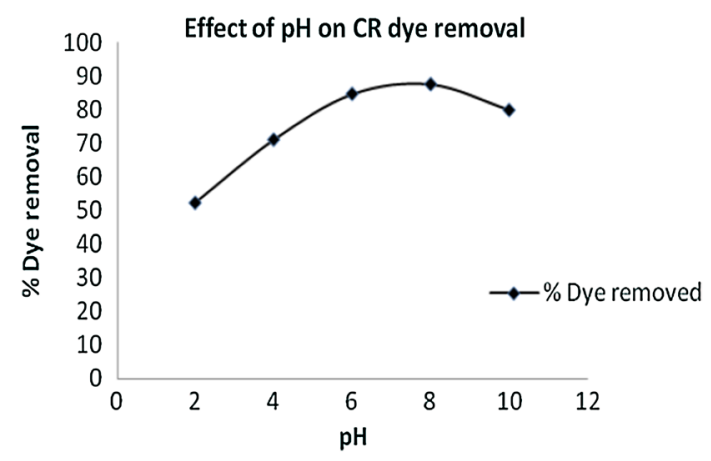

Fig. 9 Effect of $\mathrm{pH}$ on CR dye removal. *Adsorbent dose-150 mg, dye concentration-20 ppm, agitation time-150 min., temperature $-30{ }^{\circ} \mathrm{C}$, volume $-100 \mathrm{ml}$ 


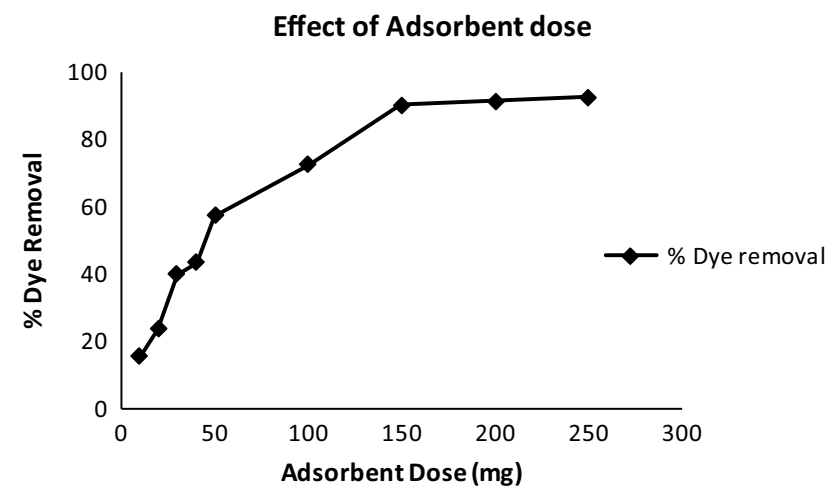

Fig. 10 Effect of adsorbent dose on CR dye removal. *Dye concentration-20 ppm, agitation time- $150 \mathrm{~min}, \mathrm{pH}-6$, temperature $-30{ }^{\circ} \mathrm{C}$, volume $-100 \mathrm{ml}$

aqueous solutions, which are shown in Figs. 11, 12 and 13, respectively. It can be observed from figures that CR dye removal efficiency of adsorbent decreased from 89.99 to $45.16 \%$ with an increase in dye concentration from 20 to $100 \mathrm{mg} / \mathrm{l}$ and maximum CR dye removal was observed at $20 \mathrm{ppm}$. The variation is mostly attributed due to aggregation of CR dye particles at higher concentration $(100 \mathrm{mg} / \mathrm{l})$, which makes it difficult to diffuse through micropores of adsorbent (Bhattacharyya and Sharma 2004). The effect of contact time on adsorption of CR dye on activated TLP was investigated at the optimized condition. Figure 12 shows that adsorption efficiency increased from 19.28 to $89.99 \%$ as the contact time changed from 20 to $150 \mathrm{~min}$ and became constant thereafter (Azhar et al. 2005) and the equilibrium was attained within $150 \mathrm{~min}$. Similarly, the adsorption of CR dye on activated TLP increases from 89.47 to $99.27 \%$ with a subsequent increase in temperature from 30 to $60^{\circ} \mathrm{C}$, which indicates the endothermic adsorption process. Due to an elevated temperature, the mobility of CR dye increases with an increase in some active sites for adsorption (Salleh

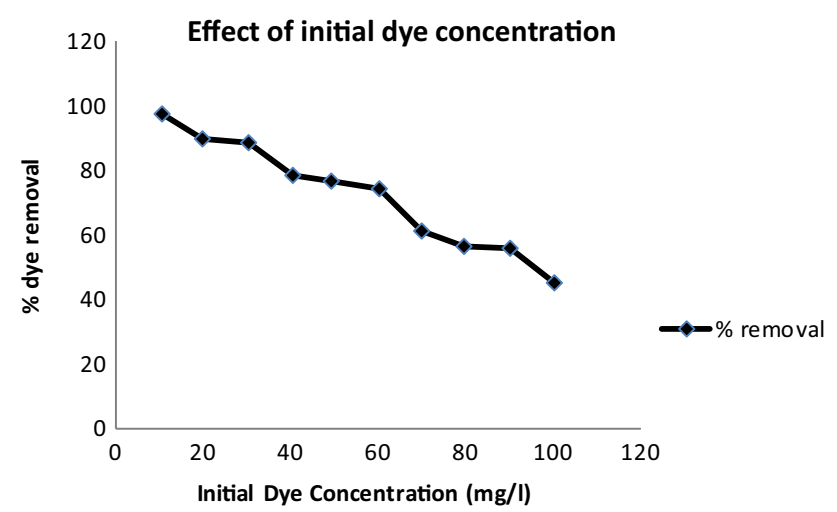

Fig. 11 Effect of initial dye concentration. *Adsorbent dose$150 \mathrm{mg}$, agitation time $-150 \mathrm{~min}, \mathrm{pH}-6$, temperature $-30{ }^{\circ} \mathrm{C}$, volume $-100 \mathrm{ml}$ et al. 2011). Furthermore, the adsorption capacity for CR dye was observed to be $33.33(\mathrm{mg} / \mathrm{g})$ for Langmuir isotherms which was found to be substantial. The comparative analysis and adsorption capacity of different adsorbents are given in Table 2. Therefore, after comparative study, it can be observed that TLP can be a good biosorbent for the removal of CR dye.

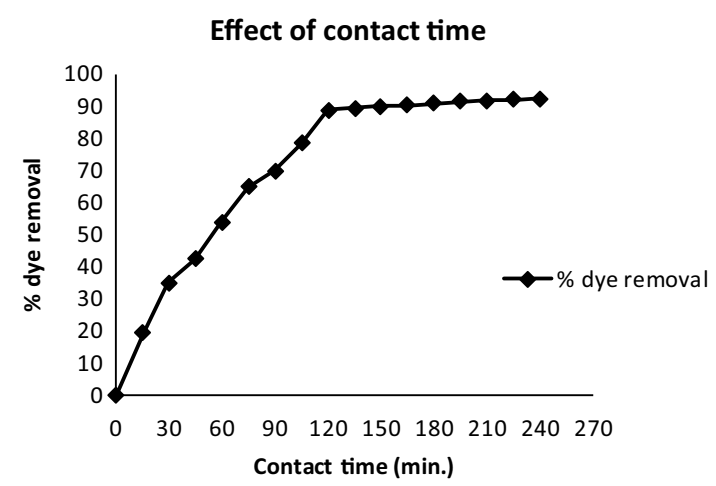

Fig. 12 Effect of contact time on CR dye removal. *Dye concentration-20 ppm, adsorbent dose-150 mg, pH-6, temperature $-30{ }^{\circ} \mathrm{C}$, volume $-100 \mathrm{ml}$

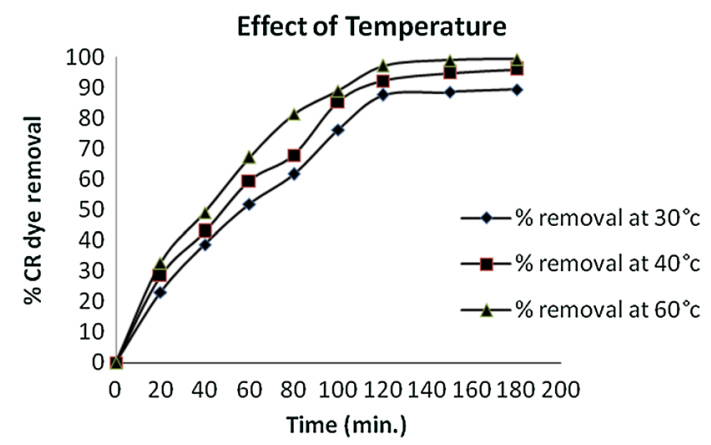

Fig. 13 Effect of temperature on CR dye removal. *Dye concentration-20 ppm, adsorbent dose-150 mg, $\mathrm{pH}-6$, contact time$150 \mathrm{~min}$, volume $-100 \mathrm{ml}$

Table 2 Adsorption capacities of CR dye on various adsorbents

\begin{tabular}{lll}
\hline Adsorbent & $\begin{array}{l}\text { Adsorbent capac- } \\
\text { ity }(\mathrm{mg} / \mathrm{g})\end{array}$ & Reference \\
\hline TLP & 33.33 & Present study \\
Cattail root & 38.79 & Hu et al. (2010) \\
Jute stick powder & 35.70 & Panda et al. (2009) \\
Sunflower stalks & $31.5-37$ & Sun and Xu (1997) \\
Wheat bran & 22.73 & Wang and Chen (2009) \\
Rice bran & 14.63 & Wang and Chen (2009) \\
Banana peel & 11.2 & Namasivayam et al. (1996) \\
\hline
\end{tabular}




\section{Equilibrium modeling}

The interaction between adsorbent and adsorbate can be very well described by adsorption isotherms (Abdelwahab 2008). Various mathematical models can be applied to explore the experimental findings of adsorption isotherms. During the present study, the adsorption of CR dye on activated TLP was modeled with the Langmuir, Freundlich and Temkin isotherms so that the mechanism and affinity of sorbent toward adsorbate can be studied in detail (Namasivayam and Kavitha 2002; Ponnusami and Srivastava 2009; Reddy et al. 2012). The different parameters for Freundlich isotherm were obtained from linear correlations of $\ln q_{\mathrm{e}}$ versus $\ln C_{\mathrm{e}}$. From Freundlich isotherms, $k_{\mathrm{f}}$, n and $R^{2}$ were observed to be $10.968,3.367$ and 0.950 , respectively. It was observed that the value of $n$ is greater than one, which indicates that adsorption is favorable (Pathania et al. 2016). The value of $1 / n$, a heterogeneity factor, lies between 0 and 1 and the $R^{2}$ value is shown in Figs. 14, 15 and 16, which shows that Langmuir isotherm model was the best fit as compared to Freundlich isotherm model. Figure 15 shows the Langmuir adsorption isotherm and the values of $q_{\mathrm{m}}$ and $K_{\mathrm{L}}$ were obtained from it. From Langmuir isotherm, the maximum sorption capacity $\left(q_{\mathrm{m}}\right)$ was found to be $33.33 \mathrm{mg} / \mathrm{g}$. Also, the significant value of the correlation coefficient, i.e., $R^{2}=0.991$, confirms the suitability and applicability of Langmuir isotherm due to the monolayer and equal distribution of CR dye on the adsorbent surface. The value of $K_{\mathrm{L}}$, i.e., $0.3572 \mathrm{~L} / \mathrm{mg}$, was then used to calculate the separation factor $\left(R_{\mathrm{L}}\right)$ (Hu et al. 2010). The calculated value of $R_{\mathrm{L}}$ was observed to be 0.5847 , indicating highly favorable adsorption process. Similarly, the Temkin isotherm highlights the equal distribution of binding energy over the adsorption sites, thus supporting the Temkin isotherm. The Temkin isotherm constants B (12.39) and A (1.497) were obtained from the plot of $q_{\mathrm{e}}$ versus $\ln C_{\mathrm{e}}$ as shown in Fig. 16. Correlation coefficient $R^{2}$ was found to be 0.929 which is

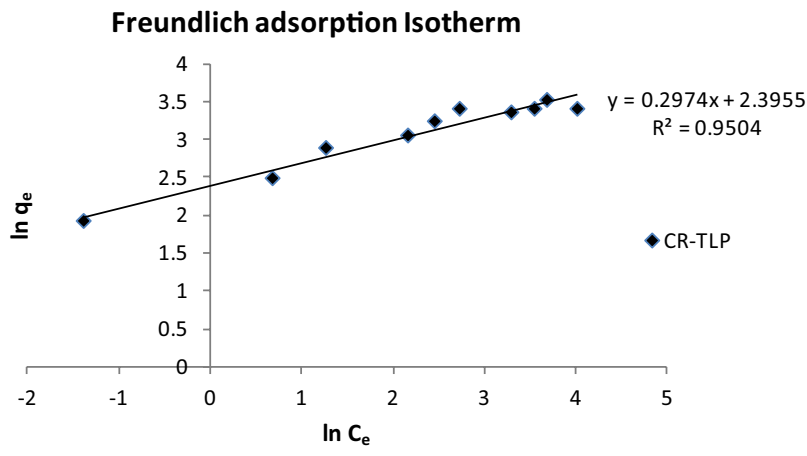

Fig. 14 Freundlich adsorption isotherm model. Temperature- $-30{ }^{\circ} \mathrm{C}$, concentration-20 ppm, adsorbent dose-150 mg, pH-6, volume- $100 \mathrm{ml}$

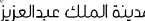
KACST

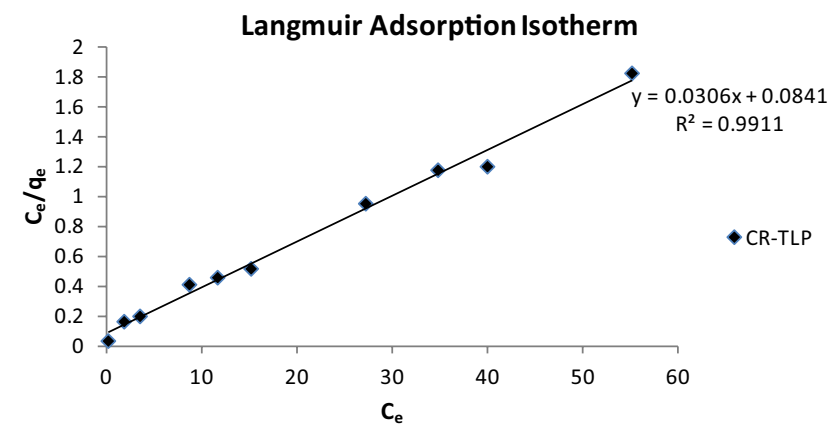

Fig. 15 Langmuir adsorption isotherm model. Temperature- $30{ }^{\circ} \mathrm{C}$, concentration-20 ppm, adsorbent dose-150 mg, pH-6, volume- $-100 \mathrm{ml}$

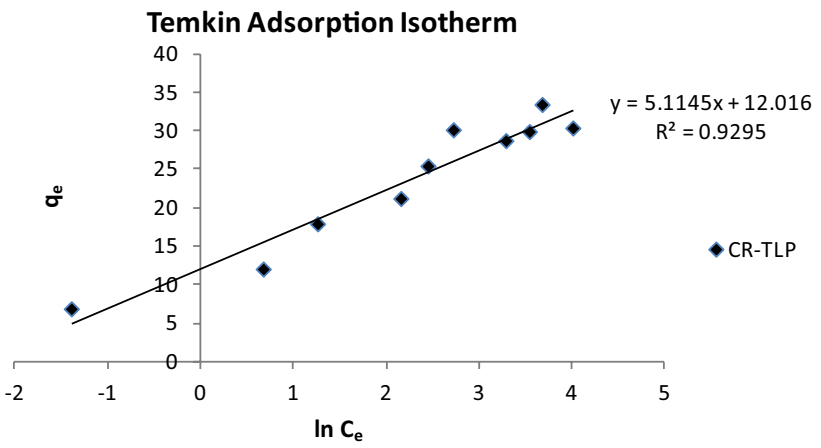

Fig. 16 Temkin adsorption isotherm model. Temperature- $30{ }^{\circ} \mathrm{C}$, concentration-20 ppm, adsorbent dose-150 mg, pH-6, volume-100 ml

lowest compared to other studied isotherms indicating its poor applicability. Table 3 shows the comparative analysis of $R^{2}$ and other values and highlights that Langmuir isotherm is the best-fit isotherm.

\section{Thermodynamic study}

Thermodynamic parameters such as $\Delta H, \Delta S$ and $\Delta G$ were used to explain the variation in dye removal efficiency with temperature (Srilakshmi and Saraf 2016). These parameters were evaluated using Eqs. 8, 9, 10 and 11. The calculated values of $\Delta H, \Delta S$ and $\Delta G$, as well as other calculated parameters, are given in Table 4 . The positive value of $\Delta S$ highlights increased randomness at solid or solution interface during the adsorption and also signifies an increase in the degree of freedom of the adsorbed species, thus favoring adsorption of CR dye. The results were in agreement with earlier findings (Ribeiro et al. 2012; Dawood and Sen 2012; Reddy et al. 2012). 
Table 3 Isotherm parameters for removal of CR dye

\begin{tabular}{|c|c|c|c|c|c|c|c|c|c|c|c|}
\hline & \multirow[t]{2}{*}{$T\left({ }^{\circ} \mathrm{C}\right)$} & \multicolumn{4}{|l|}{ Langmuir } & \multicolumn{3}{|c|}{ Freundlich } & \multicolumn{3}{|c|}{ Temkin } \\
\hline & & $q_{\mathrm{m}}(\mathrm{mg} / \mathrm{g})$ & $K_{\mathrm{L}}$ & $R^{2}$ & $R_{\mathrm{L}}$ & $k_{\mathrm{f}}$ & $n$ & $R^{2}$ & A & B & $R^{2}$ \\
\hline TLP & $30^{\circ} \mathrm{C}$ & 33.33 & 0.3572 & 0.991 & 0.5847 & 10.968 & 3.367 & 0.950 & 1.497 & 12.39 & 0.929 \\
\hline
\end{tabular}

Table 4 Thermodynamic parameters for the adsorption of CR on activated TLP

\begin{tabular}{lccccc}
\hline $\begin{array}{l}\text { Tempera- } \\
\text { ture }\left({ }^{\circ} \mathrm{C}\right)\end{array}$ & $K_{\mathrm{D}}=C_{\mathrm{s}} / C_{\mathrm{e}}$ & $\Delta G=\Delta H-T \Delta S$ & $\Delta G=-R T \ln K_{\mathrm{D}}$ & $\Delta S$ & $\Delta H$ \\
\hline 30 & 7.711790393 & -5101.071328 & -5145.978273 & & \\
40 & 17.83820113 & -7568.999088 & -7498.065175 & 246.792776 & 69677.1398 \\
60 & 92.44278689 & $-12,504.85461$ & $-12,532.14488$ & & \\
\hline
\end{tabular}

\section{Kinetic study}

The adsorption process was influenced by physical, chemical characteristics of adsorbent and experimental conditions. During the present investigation, various kinetic models which include pseudo-first and second order, Elovich kinetic model, Bhattacharya-Venkobachar kinetic model and intraparticle diffusion model were investigated in detail.

The pseudo-first-order kinetic model was explored by using an equation of a $\log \left(q_{\mathrm{e}}-q_{t}\right)$ versus $t$ at different temperatures. The pseudo-first-order rate constants, i.e., $\mathrm{k}_{1}$ and $q_{\mathrm{e}}$, were obtained from the graph of $\ln \left(q_{\mathrm{e}}-q_{t}\right)$ versus $t$ as shown in Fig. 17. During pseudo-first-order kinetic model, the observed correlation coefficient $\left(R^{2}\right)$ values were very low (0.778-0.904), which highlights that the pseudo-firstorder kinetic model did not significantly effect the adsorption of CR dye on activated TLP. The experimental kinetic data were then further analyzed using pseudo-second-order kinetic model. The pseudo-second-order rate constants, i.e., $\mathrm{k}_{2}$ and $q_{\mathrm{e}}$, were obtained from the graph of $t / q_{t}$ versus $t$ as shown in Fig. 18. The observed correlation coefficient $\left(R^{2}\right)$ was also very

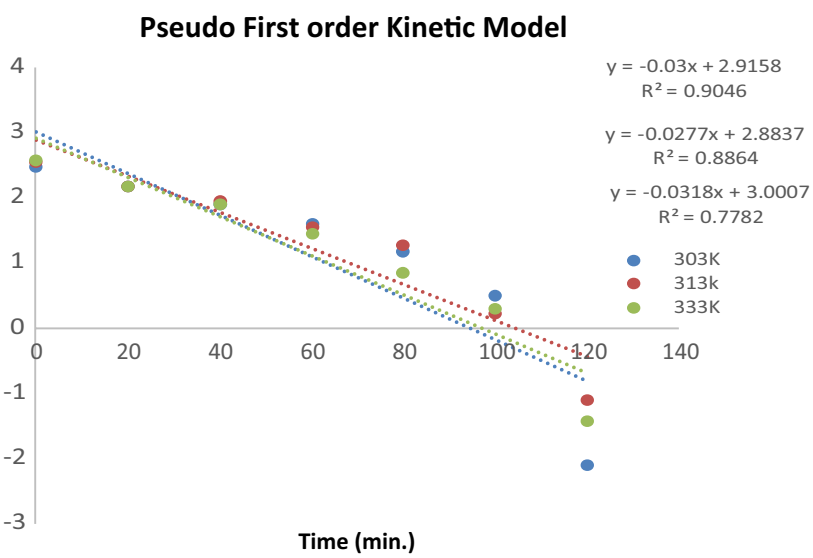

Fig. 17 Pseudo-first-order kinetic model. Temperature-30, 40, $60{ }^{\circ} \mathrm{C}$, concentration $-20 \mathrm{ppm}$, time $-180 \mathrm{~min}, \mathrm{rpm}-100$, adsorbent dose- $150 \mathrm{mg}$, volume- $100 \mathrm{ml}$

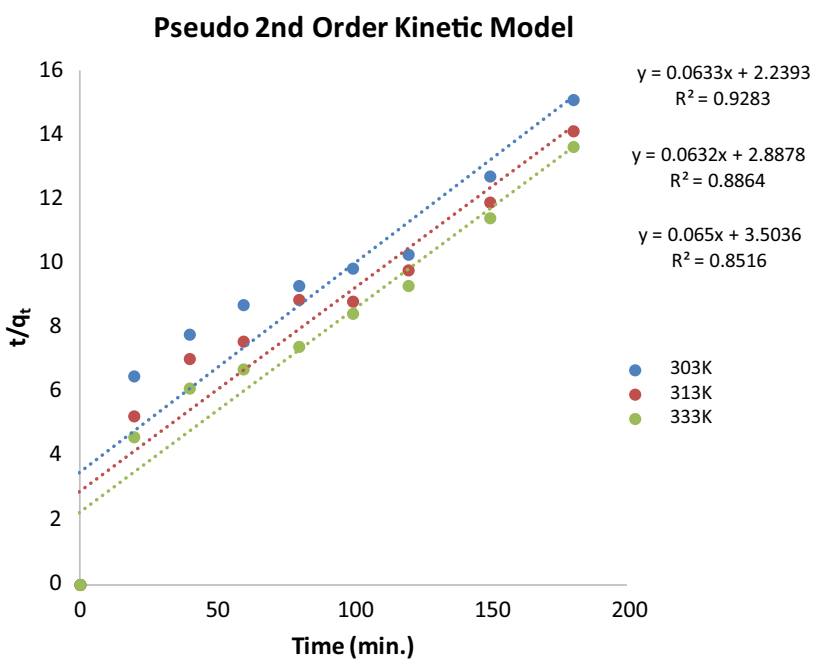

Fig. 18 Pseudo-second-order kinetic model. Temperature-30, 40, $60{ }^{\circ} \mathrm{C}$, concentration-20 ppm, time- $180 \mathrm{~min}$, rpm-100, adsorbent dose-150 mg, volume- $100 \mathrm{ml}$

low (0.778-0.904). The calculated pseudo-first- and secondorder rate constants for different temperatures conditions are given in Tables 5 and 6 , respectively. It is important to note that during the study, neither the pseudo-first-order nor the pseudo-second-order model significantly describes the adsorption of CR dye on activated TLP. Therefore, the kinetic results were analyzed via Elovich as well as Bhattacharya-Venkobachar model. The Elovich model can be studied using Eq. 12 (Oladoja et al. 2008).

$q_{t}=\frac{1}{\beta} \ln (\alpha \beta)+\frac{1}{\beta} \ln (t)$

where $q_{t}$ is dye amount adsorbed at time $t(\mathrm{mg} / \mathrm{g}), \alpha$ is adsorption rate at the initial $(\mathrm{mg} / \mathrm{min}$.), $\beta$ is the extent of surface coverage as well as activated energy $(\mathrm{g} / \mathrm{mg})$ and $t$ is contact time (min.). The Elovich constant values, i.e., $\alpha$ and $\beta$, were determined from the slope and intercept of the graph shown in Fig. 19 with correlation coefficient $\left(R^{2}\right)$ values in 
Table 5 Pseudo-first-order values for different temperature conditions
Table 6 Pseudo-second-order values for different temperature conditions

\begin{tabular}{|c|c|c|c|c|c|c|}
\hline Time (min) & $q_{t}\left(30^{\circ} \mathrm{C}\right)$ & $q_{t}\left(40^{\circ} \mathrm{C}\right)$ & $q_{t}\left(60^{\circ} \mathrm{C}\right)$ & $\ln \left(q_{\mathrm{e}}-q_{t}\right)\left(30^{\circ} \mathrm{C}\right)$ & $\ln \left(q_{\mathrm{e}}-q_{t}\right)\left(40^{\circ} \mathrm{C}\right)$ & $\ln \left(q_{\mathrm{e}}-q_{t}\right)\left(60{ }^{\circ} \mathrm{C}\right)$ \\
\hline 0 & 0.0000 & 0.0000 & 0.0000 & 2.4658 & 2.5332 & 2.5770 \\
\hline 20 & 3.0800 & 3.8025 & 4.3504 & 2.1626 & 2.1738 & 2.1756 \\
\hline 40 & 5.1533 & 5.6964 & 6.5383 & 1.8901 & 1.9311 & 1.8900 \\
\hline 60 & 6.9067 & 7.9055 & 8.9443 & 1.5824 & 1.5451 & 1.4383 \\
\hline 80 & 8.5867 & 9.0094 & 10.8116 & 1.1590 & 1.2766 & 0.8528 \\
\hline 100 & 10.1400 & 11.3569 & 11.8277 & 0.4906 & 0.2126 & 0.2852 \\
\hline 120 & 11.6533 & 12.2626 & 12.9170 & -2.1203 & -1.1051 & -1.4241 \\
\hline 150 & 11.7733 & 12.5938 & 13.1577 & 0.0000 & 0.0000 & 0.0000 \\
\hline 180 & 11.9000 & 12.7627 & 13.2029 & -0.0107 & -0.0133 & -0.0034 \\
\hline
\end{tabular}

\begin{tabular}{lcccccc}
\hline Time $(\min )$ & $q_{t}\left(30{ }^{\circ} \mathrm{C}\right)$ & $q_{t}\left(40{ }^{\circ} \mathrm{C}\right)$ & $q_{t}\left(60{ }^{\circ} \mathrm{C}\right)$ & $\frac{t}{q_{t}}\left(30{ }^{\circ} \mathrm{C}\right)$ & $\frac{t}{q_{t}}\left(40{ }^{\circ} \mathrm{C}\right)$ & $\frac{t}{q_{t}}\left(60{ }^{\circ} \mathrm{C}\right)$ \\
\hline 0 & 0.0000 & 0.0000 & 0.0000 & 0.0000 & 0.0000 & 0.0000 \\
20 & 3.0800 & 3.8025 & 4.3504 & 6.4935 & 5.2597 & 4.5972 \\
40 & 5.1533 & 5.6964 & 6.5383 & 7.7620 & 7.0220 & 6.1178 \\
60 & 6.9067 & 7.9055 & 8.9443 & 8.6873 & 7.5896 & 6.7082 \\
80 & 8.5867 & 9.0094 & 10.8116 & 9.3168 & 8.8796 & 7.3995 \\
100 & 10.1400 & 11.3569 & 11.8277 & 9.8619 & 8.8052 & 8.4547 \\
120 & 11.6533 & 12.2626 & 12.9170 & 10.2975 & 9.7859 & 9.2901 \\
150 & 11.7733 & 12.5938 & 13.1577 & 12.7407 & 11.9107 & 11.4002 \\
180 & 11.9000 & 12.7627 & 13.2029 & 15.1261 & 14.1036 & 13.6334 \\
\hline
\end{tabular}

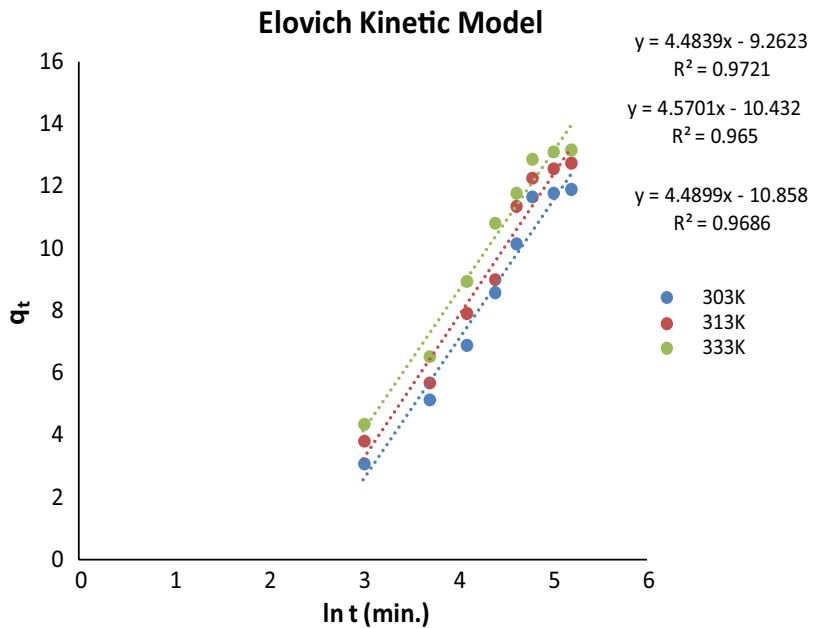

Fig. 19 Elovich kinetic model. Temperature-30, 40, $60{ }^{\circ} \mathrm{C}$, concentration-20 ppm, time-180 min, rpm-100, adsorbent dose$150 \mathrm{mg}$, volume $-100 \mathrm{ml}$

the range of $0.965-0.972$. The model confirms the suitability and applicability of Elovich kinetic for CR dye adsorption.

The Bhattacharya-Venkobachar model is expressed as shown in Eq. 13 (Okoli et al. 2015)

$U_{t}=\frac{C_{0}-C_{t}}{C_{0}-C_{\mathrm{e}}}$

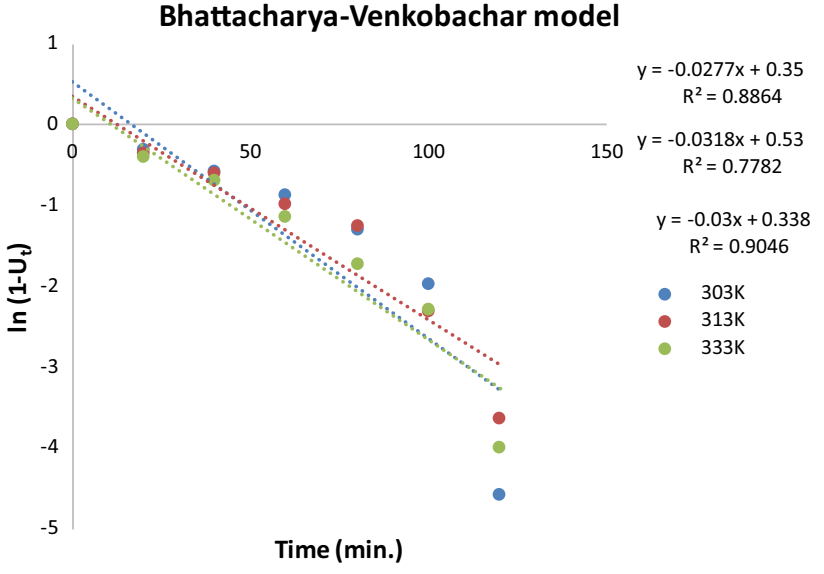

Fig. 20 Bhattacharya-Venkobachar model. Temperature-30, 40, $60{ }^{\circ} \mathrm{C}$, concentration $-20 \mathrm{ppm}$, time $-180 \mathrm{~min}, \mathrm{rpm}-100$, adsorbent dose-150 mg, volume-100 ml

whereas the effective diffusion coefficient can be obtained from Eq. 14

$D_{2}=\frac{k_{\mathrm{B}} r^{2}}{\pi^{2}}$

where $k_{\mathrm{B}}$ is the rate constant, $r$ is the particle radius $(\mathrm{m})$, $C_{0}$ is the initial concentration $(\mathrm{mg} / \mathrm{l}), C_{\mathrm{e}}$ is the equilibrium 


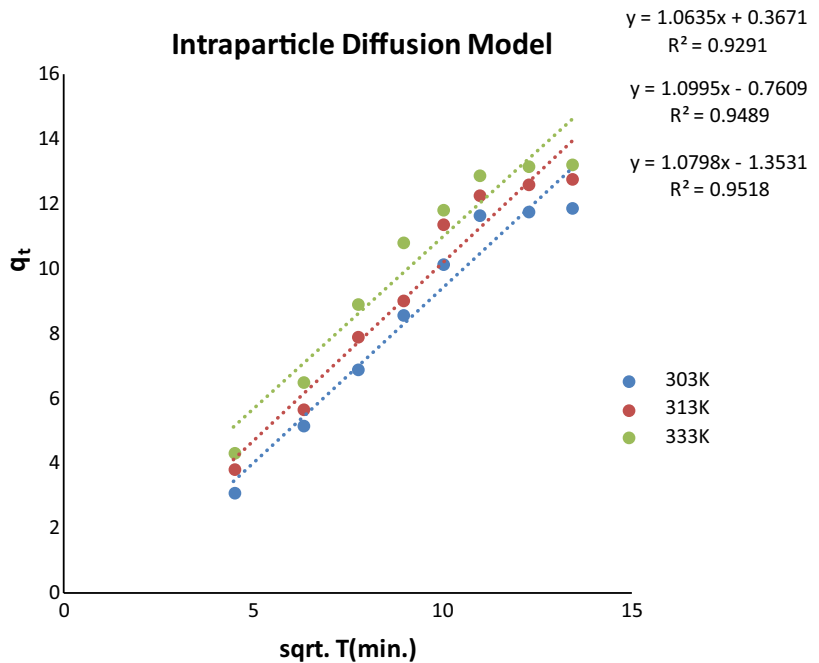

Fig. 21 Intraparticle diffusion model. Temperature-30, 40, $60{ }^{\circ} \mathrm{C}$, concentration-20 ppm, time-180 min, rpm-100, adsorbent dose $-150 \mathrm{mg}$, volume $-100 \mathrm{ml}$

concentration $(\mathrm{mg} / \mathrm{l}), C_{t}$ is the equilibrium concentration at time $t(\mathrm{mg} / \mathrm{l}), U_{t}$ is the Bhattacharya-Venkobachar constant, $D_{2}$ is an effective diffusion coefficient, $t$ is the contact time (min) and $\pi$ is the mathematical constant. The Bhattacharya-Venkobachar rate constants $\left(k_{\mathrm{B}}\right)$ for adsorbent at different temperatures were determined from the graph as shown in Fig. 20. The value of the correlation coefficient $\left(R^{2}\right)$ was observed in the range of 0.778-0.904, which shows that the model is not fit and suitable for CR dye adsorption. Furthermore, the intra-particle diffusion model was also used as shown in Eq. 15 (Weber 1972).

$q_{t}=k t^{0.5}+C_{t}$

where $q_{t}$ is the dye adsorbed quantity at time $t(\mathrm{mg} / \mathrm{g}), k$ is the rate constant of the model $(\mathrm{g} / \mathrm{mg} / \mathrm{min}), C_{t}$ is the equilibrium concentration $(\mathrm{mg} / \mathrm{l})$ and $t$ is the contact time ( $\mathrm{min}$ ). The intra-particle diffusion rate constants, i.e., $\mathrm{k}$ and $C_{t}$, at different temperatures were determined from the slope and intercept of the graph as shown in Fig. 21. The values of the correlation coefficient $\left(R^{2}\right)$ ranges from 0.929 to 0.951 for $\mathrm{CR}$ dye as temperature varied from 30 to $60^{\circ} \mathrm{C}$. The significant values of correlation coefficients confirm the suitability and applicability of intra-particle diffusion models.

\section{Conclusion}

The present investigation explores the effect of various physicochemical factors on adsorption efficiency along with kinetic, thermodynamics and equilibrium studies. It was observed that the percent removal of CR dye increases with increasing adsorbent dosage and subsequently decreases with an increase in initial dye concentration. The percentage removal of dye found to increase initially with temperature and then show no further significant increase in uptake. Equilibrium isotherms were studied for Langmuir, Freundlich and Temkin isotherm. However, the correlation coefficient $\left(R^{2}=0.991\right)$ value was observed to be best suitable for Langmuir isotherm. The Langmuir adsorption isotherms observed to be the best fit suitable with adsorption capacity of $33.33(\mathrm{mg} / \mathrm{g})$. The adsorption kinetics was also determined via pseudo-first- and second-order model, Elovich model, Bhattacharya-Venkobachar model and intra-particle diffusion model. The Elovich and intra-particle diffusion models were observed to be best fit suitable based on the correlation coefficient values. The findings of the thermodynamic study also indicate that the adsorption of CR dye on activated TLP was feasible, spontaneous and endothermic in nature. Results of the present study indicate that activated TLP has a potential for removal of CR dye. Furthermore, the feasibility and the practical use of TLP as an effective adsorbent need to be explored in detail.

Acknowledgements The authors would like to thank Director, National Institute of Industrial Engineering (NITIE), Mumbai, India, for support to conduct the research studies.

Open Access This article is distributed under the terms of the Creative Commons Attribution 4.0 International License (http://creativeco mmons.org/licenses/by/4.0/), which permits unrestricted use, distribution, and reproduction in any medium, provided you give appropriate credit to the original author(s) and the source, provide a link to the Creative Commons license, and indicate if changes were made.

\section{References}

Abdelwahab O (2008) Evaluation of the use of loofa activated carbons as potential adsorbents for aqueous solutions containing dye. Desalination 222(1-3):357-367. https://doi.org/10.1016/j.desal .2007 .01 .146

Azhar SS, Liew AG, Suhardy D, Hafiz KF, Hatim MDI (2005) Dye removal from aqueous solution by using adsorption on treated sugarcane bagasse. Am J Appl Sci 2(11):1499-1503. https://doi. org/10.3844/ajassp.2005.1499.1503

Bhattacharyya KG, Sharma A (2004) Azadirachta indica leaf powder as an effective biosorbent for dyes: a case study with aqueous Congo Red solution. J Environ Manag 71(3):217-229. https://doi. org/10.1016/j.jenvman.2004.03.002

Bhattacharyya KG, Sharma A (2005) Kinetics and thermodynamics of methylene blue adsorption on Neem (Azadirachta Indica) leaf powder. Dyes Pigment 65(1):51-59. https://doi.org/10.1016/j. dyepig.2004.06.016

Chatterjee S, Lee DS, Lee MW, Woo SH (2009) Enhanced adsorption of Congo Red from aqueous solutions by chitosan hydrogel beads impregnated with cetyltrimethyl ammonium bromide. Biores Technol 100(11):2803-2809. https://doi.org/10.1016/j. biortech.2008.12.035

Chatterjee S, Lee MW, Woo SH (2010) Adsorption of Congo Red by chitosan hydrogel beads impregnated with carbon nanotubes.

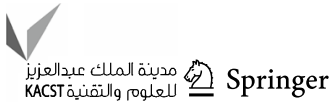


Biores Technol 101(6):1800-1806. https://doi.org/10.1016/j.biort ech.2009.10.051

Chen KC, Wu JY, Yang WB, Hwang SC (2003) Evaluation of effective diffusion coefficient and intrinsic kinetic parameters on azo dye biodegradation using PVA-immobilized cell beads. Biotechnol Bioeng 83(7):821-832. https://doi.org/10.1002/bit.10730

Dawood S, Sen TK (2012) Removal of anionic dye Congo Red from aqueous solution by raw pine and acid-treated pine cone powder as adsorbent: equilibrium, thermodynamic, kinetics, mechanism and process design. Water Res 46(6):1933-1946. https://doi. org/10.1016/j.watres.2012.01.009

Fan L, Zhou Y, Yang W, Chen G, Yang F (2008) Electrochemical degradation of aqueous solution of Amaranth azo dye on ACF under potentiostatic model. Dyes Pigments 76(2):440-446. https://doi. org/10.1016/j.dyepig.2006.09.013

Forgacs E, Cserháti T, Oros G (2004) Removal of synthetic dyes from wastewaters: a review. Environ Int 30(7):953-971. https ://doi.org/10.1016/j.envint.2004.02.001

Garg VK, Gupta R, Yadav AB, Kumar R (2003) Dye removal from aqueous solution by adsorption on treated sawdust. Biores Technol 89(2):121-124. https://doi.org/10.1016/S0960 -8524(03)00058-0

Gupta VK, Suhas (2009) Application of low-cost adsorbents for dye removal-a review. J Environ Manage 90(8):2313-2342. https ://doi.org/10.1016/j.jenvman.2008.11.017

Hameed BH (2009) Removal of cationic dye from aqueous solution using jackfruit peel as non-conventional low-cost adsorbent. J Hazardous Mater 162(1):344-350. https://doi.org/10.1016/j. jhazmat.2008.05.045

Hameed BH (2010) Evaluation of papaya seed as a novel non-conventional low-cost adsorbent for removal of methylene blue. J Hazardous Mater 162(2-3):939-994. https://doi.org/10.1016/j. jhazmat.2008.05.120

Hesas RH, Niya AA, Daud WMAW, Sahu JN (2013) Preparation and characterization of activated carbon from apple waste by microwave-assisted phosphoric acid activation: application in methylene blue adsorption. Bioresources 8(2):2950-2966. https ://doi.org/10.15376/biores.8.2.2950-2966

Ho YS, Mckay G (1998) Kinetic models for the sorption of dye from aqueous solution by wood. Process Saf Environ Prot 76(2):183191. https://doi.org/10.1205/095758298529326

Hu Z, Chen H, Ji F, Yuan S (2010) Removal of Congo Red from aqueous solution by cattail root. J Hazardous Mater 173(13):292-297. https://doi.org/10.1016/j.jhazmat.2009.08.082

Ibrahim MB, Sulaiman MS, Sani S (2015) Assessment of adsorption properties of neem leaves wastes for the removal of Congo Red and methyl orange. In: 3rd international conference on biological, chemical \& environmental sciences (BCES-2015) Kuala Lumpur (Malaysia). http://iicbe.org/upload/1272C0915067.pdf. Accessed 13 Nov 2017

Kaur S, Rani S, Mahajan RK (2013) Adsorption kinetics for the removal of hazardous dye Congo Red by biowaste materials as adsorbents. J Chem 2013:12. https://doi. org/10.1155/2013/628582

King P, Srinivas P, Kumar YP, Prasad VS (2006) Sorption of copper (II) ion from aqueous solution by Tectona grandis. J Hazard Mater 136(3):560-566. https://doi.org/10.1016/j.jhazm at.2005.12.032

Magriotis ZM, Vieira SS, Saczk A, Santos NAV, Ramos SN (2014) Removal of dyes by lignocellulose adsorbents originating from biodiesel production. J Environ Chem Eng 2(4):2199-2210. https://doi.org/10.1016/j.jece.2014.09.012

Mondal S (2008) Methods of dye removal from dye house effluent-an overview. Environ Eng Sci 25(3):383-396. https://doi. org/10.1089/ees.2007.0049
Muthusamy S, Venkatachalam S, Jeevamani PM, Rajarathinam N (2014) Biosorption of $\mathrm{Cr}(\mathrm{VI})$ and $\mathrm{Zn}$ (II) ions from aqueous solution onto the solid biodiesel waste residue: mechanistic, kinetic and thermodynamic studies. Environ Sci Pollut Res 21(1):593-608. https://doi.org/10.1007/s11356-013-1939-8

Namasivayam C, Kavitha D (2002) Removal of Congo Red from water by adsorption onto activated carbon prepared from coir pith, an agricultural solid waste. Dyes Pigments 54(1):47-58. https://doi.org/10.1016/S0143-7208(02)00025-6

Namasivayam C, Muniasamy N, Gayatri K, Rani M, Ranganathan K (1996) Removal of dyes from aqueous solutions by cellulosic waste orange peel. Biores Technol 57(1):37-43. https://doi. org/10.1016/0960-8524(96)00044-2

Nasuha N, Zurainan HZ, Maarof HI, Zubir NA, Amri N (2011) Effect of cationic and anionic dye adsorption from aqueous solution by using chemically modified papaya seed. In: International conference on environmental science and engineering IPCBEE, vol 8 IACSIT Press, Singapore. https://pdfs.seman ticscholar.org/38ee/471ca9de67b594f739dbe1a910eebf2f60d a.pdf. Accessed 9 Oct 2017

Okoli CA, Onukwuli OD, Okey-Onyesolu CF, Okoye CC (2015) adsorptive removal of dyes from synthetic wastewater using activated carbon from tamarind seed. Eur Sci J. https://doi. org/10.19044/esj.2015.v11n18p\%25p

Oladoja NA, Aboluwoye CO, Oladimeji YB (2008) Kinetics and isotherm studies on methylene blue adsorption onto ground palm kernel coat. Turkish J Eng Environ Sci 32:303-312

Panda GC, Das SK, Guha AK (2009) Jute stick powder as a potential biomass for the removal of Congo Red and rhodamine B from their aqueous solution. J Hazardous Mater 164(1):374-379. https://doi.org/10.1016/j.jhazmat.2008.08.015

Pathania D, Sharma A, Siddiqi ZM (2016) Removal of Congo Red dye from aqueous system using Phoenix dactylifera seeds. J Mol Liq 219:359-367. https://doi.org/10.1016/j.molliq.2016.03.020

Ponnusami V, Srivastava SN (2009) Studies on application of teak leaf powders for the removal of color from synthetic and industrial effluents. J Hazard Mater 169:1159-1162. https://doi. org/10.1016/j.jhazmat.2009.03.142

Ponnusami V, Vikram S, Srivastava SN (2008) Guava (Psidium guajava) leaf powder: novel adsorbent for removal of methylene blue from aqueous solutions. J Hazardous Mater 152(1):276286. https://doi.org/10.1016/j.jhazmat.2007.06.107

Reddy MCS, Sivaramakrishna L, Reddy AV (2012) The use of an agricultural waste material, Jujuba seeds for the removal of anionic dye (Congo Red) from aqueous medium. J Hazard Mater 203-204:118-127. https://doi.org/10.1016/j.jhazm at.2011.11.083

Ribeiro RFL, Soares VC, Costa L, Nascentes CC (2012) Efficient removal of $\mathrm{Cd}^{2+}$ from aqueous solutions using by-product of biodiesel production. J Hazardous Mater 237-238:170-179. https://doi.org/10.1016/j.jhazmat.2012.08.027

Rouf S, Nagapadma M, Rao RR (2015) Removal of harmful textile dye Congo Red from aqueous solution using chitosan and chitosan beads modified with CTAB. Int J Eng Res Appl 5(3 (Part-2)):75-82

Salleh MAM, Mahmoud DK, Karim WA, Idris A (2011) Cationic and anionic dye adsorption by agricultural solid wastes: a comprehensive review. Desalination 280(1-3):1-13. https://doi. org/10.1016/j.desal.2011.07.019

Silva MMF, Oliveira MM, Avelino MC, Fonseca MG, Almeida RKS Filho SEC (2012) Adsorption of an industrial anionic dye by modified-KSF-montmorillonite: evaluation of the kinetic, thermodynamic and equilibrium data. Chem Eng J 203:259-268. https://doi.org/10.1016/j.cej.2012.07.009 
Singh DK, Srivastava B (1999) Removal of basic dyes from aqueous solutions by chemically treated Psidium guajava leaves. Indian J Environ Health 41(4):333-345

Singh A, Dutta DP, Ramkumar J, Bhattacharya K, Tyagi AK, Fulekar MH (2013) Serendipitous discovery of super adsorbent properties of sonochemically synthesized nano $\mathrm{BaWO}_{4}$. RSC Adv 3:22580-22590. https://doi.org/10.1039/C3RA44350G

Srilakshmi C, Saraf R (2016) Ag-doped hydroxyapatite as efficient adsorbent for removal of Congo Red dye from aqueous solution: synthesis, kinetic and equilibrium adsorption isotherm analysis. Microporous Mesoporous Mater 219:134-144. https://doi. org/10.1016/j.micromeso.2015.08.003

Sun G, Xu X (1997) Sunflower stalks as adsorbents for color removal from textile wastewater. Ind Eng Chem Res 36(3):808-812. https://doi.org/10.1021/ie9603833
Wang XS, Chen JP (2009) Biosorption of Congo Red from aqueous solution using wheat bran and rice bran: batch studies. Sep Sci Technol 44(6):1452-1466. https://doi.org/10.1080/0149639090 2766132

Weber WJ Jr (1972) Physicochemical processes: for water quality control. Wiley, New York, pp 199-259. https://doi.org/10.1002/ aic. 690190245

Zhou J, Tang C, Cheng B, Yu J, Jaroniec M (2012) Rattle-type carbonalumina core-shell spheres: synthesis and application for adsorption of organic dyes. ACS Appl Mater Interf 4(4):2174-2179. https://doi.org/10.1021/am300176k

Publisher's Note Springer Nature remains neutral with regard to jurisdictional claims in published maps and institutional affiliations. 